\title{
Associations of Spouse Involvement and Women Empowerment with Antenatal Care Utilization; A Cross-Sectional Study
}

\author{
${ }^{1}$ Noha Eladawi, ${ }^{1}$ Randah Helal, ${ }^{1}$ Nadia Abd El-Hamed Montasser, ${ }^{2}$ Ahmed Gibreel \\ ${ }^{1}$ Department of Public Health and Community Medicine, ${ }^{2}$ Department of obstetrics and \\ gynecology Faculty of Medicine, Mansoura University, Mansoura, Egypt.
}

\begin{abstract}
Background: Utilization of prenatal health services is associated with improved pregnancy outcomes, including reduced maternal and perinatal mortality. Objective: to assess antenatal care (ANC) utilization and to investigate its relation to spouse involvement and women empowerment. Method: A cross-sectional study was carried out among 500 females attending an immunization clinic for the purpose of immunizing their babies who were delivered within the previous six months in 4 urban and rural primary care centers in Mansoura district from September 2017 to January 2018. Results: The mean age of the

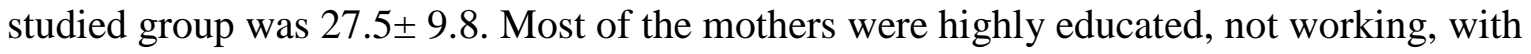
enough to just enough income, unaccompanied with their husbands who had a positive attitude towards ANC. Approximately $68.6 \%$ of the mothers had $\geq 4$ ANC visits. Better ANC utilization ( $\geq 4$ visits) was significantly associated with living in urban areas, higher education, working status, enough income, an accompanying spouse, and a positive attitude of the spouse. Mothers had moderate empowerment (5.6 \pm 2.3 out of 9 ). Total empowerment score was significantly higher among mothers who had $\geq 4$ compared with $<4$ ANC visits (5.9 \pm 2.1 versus $4.8 \pm 2.5)$. Conclusion: Spouse involvement and women empowerment have a positive impact on antenatal care utilization.
\end{abstract}

Keywords: Antenatal care utilization, empowerment, spouse involvement.

Correspondent Author: Randah Helal E-mail: ranhel2000@yahoo.com

\section{Introduction}

Complications during pregnancy can contribute to acute and chronic maternal and fetal morbidity and mortality. ${ }^{1}$ Globally, one-third of maternal deaths are directly linked to inadequate antenatal care (ANC). ${ }^{2}$ It is an essential component of maternal health which aids to identify such complications and potential risks during pregnancy and to plan for a safe delivery. ${ }^{2}$ Additionally, ANC, comprising the identification and management of comorbid diseases and obstetric complications, assists future mothers to give birth to a healthy baby and helps to decrease the risk of maternal morbidity or mortality. ${ }^{3,4}$ Efficient ANC services help the future mother in preparing for birth and avoiding care-seeking delays for obstetric emergencies. ${ }^{5}$ Utilization of prenatal health services is associated with improved pregnancy outcomes, including reduced maternal and perinatal mortality. ${ }^{6}$ Mother-child mortality and morbidity rates are quite high in Egypt compared to developed countries. ${ }^{7}$ Although much has been done to enhance the delivery of mother-child health care in Egypt, lowquality services, insufficient facilities, and social disparity regarding the access of maternal health services persist. ${ }^{7}$ Therefore, in Egypt and probably most developing countries, the utilization of ANC services is very limited and often delayed due to several barriers including demographic, economic, educational, cultural and geographic barriers. ${ }^{7}$ It has been suggested that husband's attendance during ANC can improve the percentages 
of institutional deliveries and postnatal service utilization, and consequently reduces maternal morbidity and mortality. ${ }^{5}$ However, socio-cultural norms that define pregnancy as a woman's domain as well as poor health worker communication and low male representation among staff have been shown to discourage men's involvement. ${ }^{8}$ Empowering women during pregnancy hasn't been also presented as another significant strategy to increase the utilization of ANC services, to reduce maternal morbidity and mortality, and to

Table 1: Socio-demographic characteristics and spouse involvement of 500 female by antenatal care utilization groups, 2017-2018

\begin{tabular}{|c|c|c|c|c|c|c|c|c|}
\hline & \multicolumn{2}{|c|}{$\begin{array}{l}<4 \text { visits } \\
(\mathrm{N}=157)\end{array}$} & \multicolumn{2}{|c|}{$\begin{array}{l}\geq 4 \text { visits } \\
(\mathrm{N}=343)\end{array}$} & \multicolumn{2}{|c|}{$\begin{array}{c}\text { Total } \\
(\mathrm{N}=500)\end{array}$} & P value* & OR (CI) \\
\hline Age $($ mean \pm SD)* & \multicolumn{2}{|c|}{$27.1 \pm 3.8$} & \multicolumn{2}{|c|}{$27.7 \pm 11.6$} & \multicolumn{4}{|c|}{0.54} \\
\hline \multicolumn{9}{|l|}{ Residence: N (\%) } \\
\hline Rural & 149 & 94.9 & 88 & 25.7 & 237 & 47.4 & \multirow{2}{*}{$<0.001$} & \multirow{2}{*}{$\begin{array}{c}53.9 \\
(25.5-114.4)\end{array}$} \\
\hline Urban & 8 & 5.1 & 255 & 74.3 & 263 & 52.6 & & \\
\hline \multicolumn{9}{|l|}{ Education: N (\%) } \\
\hline Read/write \& illiterate® & 58 & 36.9 & 17 & 5.0 & 75 & 15.0 & \multirow{3}{*}{$<0.001$} & \\
\hline Elementary/Secondary & 92 & 58.6 & 115 & 33.6 & 207 & 41.4 & & $\begin{array}{c}4.26 \\
(2.2-8.2)\end{array}$ \\
\hline University \& higher & 7 & 4.5 & 211 & 61.5 & 218 & 43.6 & & $\begin{array}{c}102.8 \\
(37.8-293.4)\end{array}$ \\
\hline \multicolumn{9}{|l|}{ Occupation: N (\%) } \\
\hline Not working $®$ & 152 & 96.8 & 273 & 79.6 & 425 & 85.0 & \multirow{2}{*}{$<0.001$} & \\
\hline Working & 5 & 3.2 & 70 & 20.4 & 75 & 15.0 & & $\begin{array}{c}7.8 \\
(2.95-22.4) \\
\end{array}$ \\
\hline \multicolumn{9}{|l|}{ Income: $\mathbf{N}(\%)$} \\
\hline $\begin{array}{l}\text { Not enough with transient } \\
\text { debit }\end{array}$ & 29 & 18.5 & 18 & 5.2 & 47 & 9.4 & \multirow{4}{*}{$-<0.001$} & \\
\hline $\begin{array}{l}\text { Not enough with } \\
\text { permanent debit }\end{array}$ & 31 & 19.7 & 17 & 5.0 & 48 & 9.6 & & $\begin{array}{c}0.88 \\
(0.4-2.0) \\
\end{array}$ \\
\hline Just enough & 76 & 48.4 & 111 & 32.4 & 187 & 37.4 & & $\begin{array}{c}2.35 \\
(1.2-4.5) \\
\end{array}$ \\
\hline Enough & 21 & 13.4 & 197 & 57.4 & 218 & 43.6 & & $\begin{array}{c}15.1 \\
(7.2-31.7) \\
\end{array}$ \\
\hline \multicolumn{9}{|l|}{ Spouse involvement: N (\%) } \\
\hline Spouse accompany & 5 & 3.2 & 83 & 24.2 & 88 & 17.6 & $<0.001$ & $\begin{array}{c}9.7 \\
(3.9-24.5) \\
\end{array}$ \\
\hline Positive attitude of spouse & 130 & 82.2 & 316 & 92.1 & 446 & 89.2 & 0.002 & $\begin{array}{c}2.43 \\
(1.32-4.47)\end{array}$ \\
\hline
\end{tabular}

$*$ Chi-square unless indicated ( $t$-test). OR (CI), odds ratio and $95 \%$ confidence interval from univariate logistic regression

Table 2: Antenatal care benefits and barriers as reported by 500 females by antenatal care reduce infant mortality. ${ }^{9,10}$ Additionally, empowering women is considered a practical sign for counteracting genderbased inequalities seen in many countries. ${ }^{11}$ ANC has an important impact on pregnancy outcomes and its utilization is affected by different factors such as male involvement, empowerment of the women, the presence of different barriers or facilitators. So, this study was conducted to assess ANC utilization and to determine its relation to spouse involvement and women empowerment. 
utilization groups, 2017-2018.

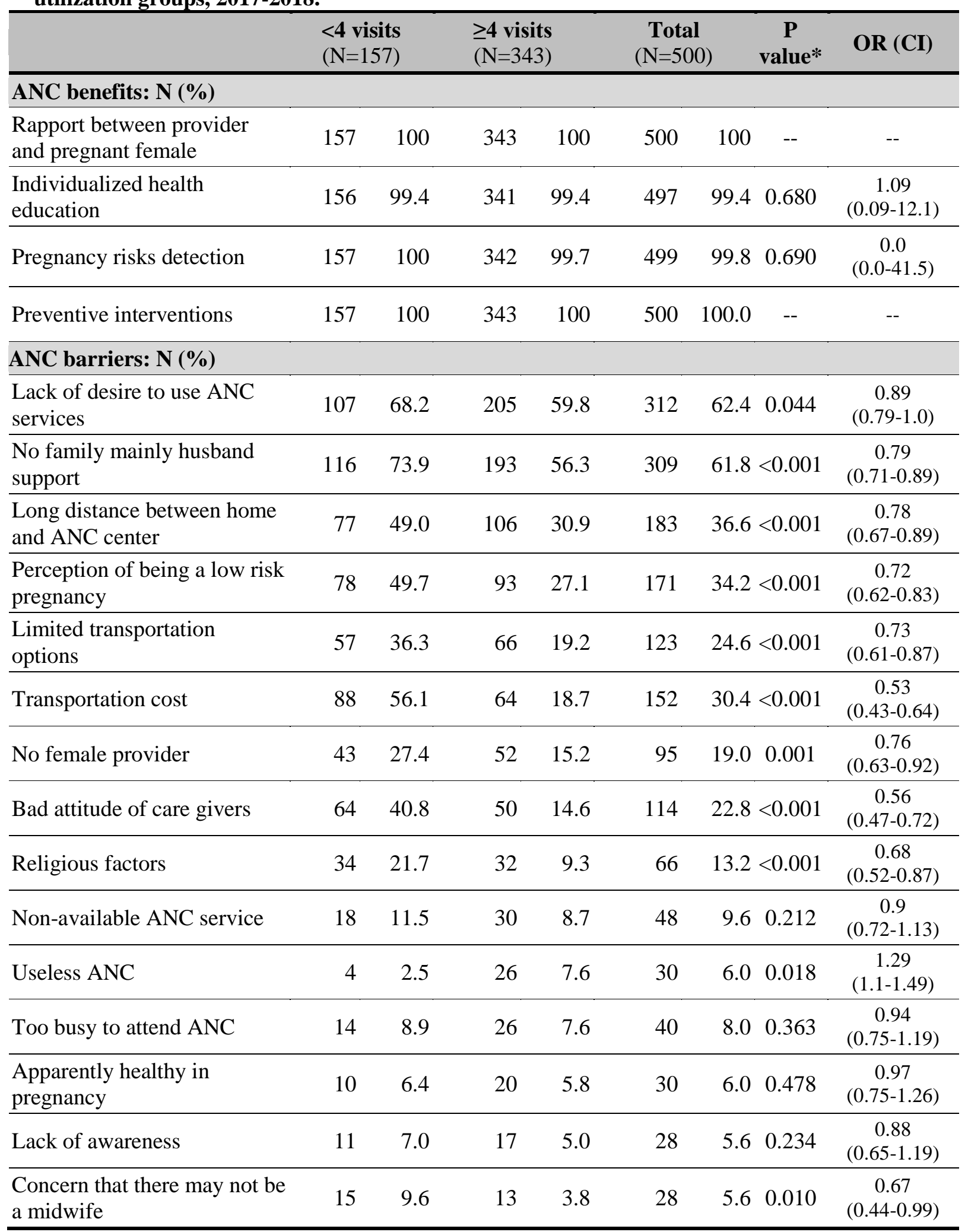

* Chi-square, OR (CI), odds ratio and $95 \%$ confidence interval from univariate logistic regression

\section{Method}

Design: This is a cross-sectional study carried out over the span of six months from September 2017 to January 2018.
The study complies with all relevant national regulations and institutional policies and has been approved by the research ethics committee of the Faculty of Medicine, Mansoura University.

Table3: Women empowerment of 500 female by antenatal care utilization groups, 2017-2018. 


\begin{tabular}{|c|c|c|c|c|}
\hline & $<4$ visits & $\geq 4$ visits & Total & P value* \\
\hline \multicolumn{5}{|c|}{ Total empowerment } \\
\hline Mean \pm SD & $4.8 \pm 2.5$ & $5.9 \pm 2.1$ & $5.6 \pm 2.3$ & \multirow{2}{*}{$<0.001$} \\
\hline Median (min-max) & $5(1-9)$ & $7(1-9)$ & $6(1-9)$ & \\
\hline \multicolumn{5}{|c|}{ Economic component } \\
\hline Mean \pm SD & $2.29 \pm 1.3$ & $2.96 \pm 1.20$ & $2.8 \pm 1.3$ & \multirow{2}{*}{$<0.001$} \\
\hline Median (min-max) & $2(0.00-4.00)$ & $4(0.00-4.00)$ & $3(0.00-4.00)$ & \\
\hline \multicolumn{5}{|c|}{ Socioeconomic component } \\
\hline Mean \pm SD & $1.13 \pm 1.08$ & $1.71 \pm 0.89$ & $1.5 \pm 0.99$ & \multirow{2}{*}{$<0.001$} \\
\hline Median (min-max) & $1(0.00-3.00)$ & $2(0.00-3.00)$ & $2(0.00-3.00)$ & \\
\hline \multicolumn{5}{|l|}{ Legal component } \\
\hline Mean \pm SD & $1.38 \pm 0.81$ & $1.32 \pm 0.68$ & $1.3 \pm 0.7$ & \multirow{2}{*}{0.132} \\
\hline Median (min-max) & $2(0.00-2.00)$ & $1(0.00-2.00)$ & $1(0.00-2.00)$ & \\
\hline
\end{tabular}

Participants: The study targeted females attending immunization setting for their babies who were delivered within the previous six months. The study was conducted in 4 urban and rural health facilities in Mansoura district, Egypt. No exclusions were followed based on age, education, socio-demographic status, or presence and absence of company.

Sample size and sampling technique: The sample size was calculated online. ${ }^{12} \mathrm{~A}$ pilot study was done on 60 females, from which the percent of female attending ANC for less than four visits was found to be $18.3 \%$. By considering the worst acceptable value as 23.3 , the sample calculated equaled 393 which then increased to reach 500 to compensate for any missing data. Systematic random sample method was used where every tenth woman attending the clinic was included in the study.

Recruitment: The authors gave a brief explanation of the objectives of the questionnaire to all the participants. Females were also assured of their anonymity and the confidentiality of their responses. Oral consent was obtained from the director of the centers and from each participant involved in the study.

Data collection tool: The attendants were asked to fill the study questionnaire which covered the following domains; (1) sociodemographic data as name, age, residence, and socioeconomic status, as described before $^{13}$ (2) ANC utilization (frequency of attendance) which was later categorized into $<4$ visits and $\geq 4$ visits ( 3 ) benefits of ANC which included rapport between provider and pregnant female, early detection of pregnancy risks, individualized health education and preventive interventions, (4) barriers to ANC utilization such as lack of desire to use ANC services, lack of means of transportation, transportation cost, distant ANC services between home and ANC centers, perception of being a low risk pregnancy, lack of available ANC services, lack of a midwife, lack of family support specially husband support, bad attitude of caregivers, having a healthy appearance, lack of awareness, lack of female provider. Additionally, the questionnaire was documenting the study outcomes (5) spouse involvement which included spouse company when attending the ANC services and the attitude towards spouse (6) women empowerment based on items of the Demographic and Health Survey $(\mathrm{DHS})^{14}$ which included (a) economic empowerment (difference between her income and partner income, who decides about her money spending, who decides about partner money spending, who decides about major household purchases), (b) socio-familial empowerment (who decides about visits to her family, who decides about her health care and asking about husband punishment if goes out without telling, if neglects children, if argues with him, if refuses sex, 
if burns food) or (c) legal empowerment (enquiring about own house or own land) and finally asks who decides family planning. It was measured as a composite score, ranging from 0 to 9 , where 9 represents "highly empowered" and 0 represents "not empowered".

Study outcomes: The main study outcome was the frequency of antenatal care visits. Statistical analysis: Categorical variables were presented as frequencies and percentages while continuous variables were presented as means and standard deviations. Chi-square or Fisher exact tests, as appropriate, were used to test significant differences of categorical variables between the study groups (high and low ANC utilization) while t-test or Mann-Whitney, as appropriate, were used to detect the significance of continuous variables between the study groups. All the significant variables in the univariate analysis were included in the multivariate logistic regression analysis (using the Forward Wald statistical technique) to detect independent factors associated with ANC utilization. The goodness of fit of the model was determined according to Rsquared value. The variables that were statistically significant were retained in the final model. All P-values were twotailed. P-value $<0.05$ was considered as significant. SPSS (Version 23.0. Armonk, NY: IBM Corp) was used for all statistical analyses.

\section{Results}

A total 500 mothers were included in the current analysis. The mean age was $27.5 \pm$ 9.8. Mothers from rural and urban residency represented approximately equal percentages (47.4\% and 52.6\%, respectively). Mothers had high levels of education as university and higher education represented $43.6 \%$ followed by Elementary/secondary $\quad 41.4 \%$ versus $15.0 \%$ who could read/write or were illiterate. Most of the mothers were not working $(85.0 \%)$ while the reported income was either enough $(43.6 \%)$ or just enough (37.4\%). Most of the spouses (89.2\%) had a positive attitude towards ANC utilization however only $17.6 \%$ accompanied their wives. About twothirds of the mothers had 4 ANC visits or more $(\mathrm{N}=343,68.6 \%)$ versus $(\mathrm{N}=157$, $31.4 \%$ ) had less than 4 visits.

Table 1 shows that, the majority of the mothers who had more than 4 ANC visits were from urban areas $(74.3 \%$ versus $5.1 \%$ ), highly educated as university and higher education represented $(61.5 \%$ versus $4.5 \%)$, working $(20.4 \%$ versus $3.2 \%$ ), with enough income ( $57.4 \%$ versus $1.4 \%)$. Regarding spouse involvement, the mothers who had more than 4 ANC visits had a higher percentage of spouse company during the ANC visits $(24.2 \%$ versus $3.2 \%$ ) and had a positive attitude towards their spouses $(92.1 \%$ versus $82.2 \%$ ).

As shown in Table 2, almost all the mothers had proper knowledge regarding the benefits of ANC where all of them $(100 \%)$ agreed on the importance of ANC visits to make a rapport between provider and pregnant females, recognized the importance of ANC preventive interventions (100\%), pregnancy risks detection $(99.8 \%)$, and individualized health education (99.4\%) in ANC settings. However, there was no significant difference between the groups $(\geq 4$ versus $<4$ ANC visits) regarding these benefits.

By studying the barriers to ANC (Table 2 ), most of the barriers were significantly lower among those who had 4 ANC visits or more such as lack of desire to use ANC services $(59.8 \%$ versus $68.2 \%)$, absence of family mainly husband support $(56.3 \%$ versus $73.9 \%$ ), long distance between home and ANC center $(30.9 \%$ versus $49.0 \%$ ), perception of being a low risk pregnancy $(27.1 \%$ versus $49.7 \%)$, limited transportation options $(19.2 \%$ versus $36.3 \%)$, transportation cost $(18.7 \%$ versus $56.1 \%)$, lack of female provider $(15.2 \%$ versus $27.4 \%$ ), bad attitude of caregivers Table 4: Multivariate logistic regression analysis of factors associated with better antenatal care utilization. 


\begin{tabular}{lcc}
\hline Characteristics & Adjusted OR & $\begin{array}{c}\text { Confidence } \\
\text { interval }\end{array}$ \\
\hline $\begin{array}{l}\text { Spouses } \\
\text { accompanying } \\
\text { mothers during } \\
\text { their ANC visit }\end{array}$ & 6.40 & $(2.3-18.1)$ \\
\hline $\begin{array}{l}\text { Urban } \\
\text { residency }\end{array}$ & 23.3 & $(8.1-56.0)$ \\
\hline $\begin{array}{l}\text { Elementary/ } \\
\text { secondary } \\
\text { education }\end{array}$ & 2.7 & $(1.3-4.9)$ \\
\hline $\begin{array}{l}\text { University } \\
\text { higher } \\
\text { education }\end{array}$ & 5.06 & $(1.5-17.1)$ \\
\hline $\begin{array}{l}\text { Transportation } \\
\text { cost }\end{array}$ & 0.49 & $(0.28-0.88)$ \\
\hline $\begin{array}{l}\text { Bad attitude of } \\
\text { care givers }\end{array}$ & 0.51 & $(0.28-0.92)$ \\
\hline
\end{tabular}

Constant $=-8.9, p<0.001$. This model predicts 85.4 , chi-square $=293.3 p=0.000$

(14.6\% versus $40.8 \%)$, religious factors ( $9.3 \%$ versus $21.7 \%$ ), concern that there may be no midwives $(3.8 \%$ versus $11.5 \%)$. Unexpectedly, considering the perception of ANC as useless (7.6\%) was the only barrier which was significantly higher among those who had 4 ANC visits or more $(6.0 \%$ versus $2.5 \%)$. On the other hand, there were no significant differences between the groups ( $\geq 4$ versus $<4$ ANC visits) regarding the lack of available ANC service, being too busy to attend ANC services, being apparently healthy in pregnancy, and lack of awareness.

As shown in Table 3, mothers had overall a moderate empowerment score $(5.6 \pm 2.3$ out of 9). The mean of total woman empowerment score was significantly higher among mothers who had 4 ANC visits or more $(5.9 \pm 2.1$ versus $4.8 \pm 2.5$, $\mathrm{p}<0.001)$. The same was observed regarding economic empowerment component $(2.96 \pm 1.20$ versus $2.29 \pm 1.3$, $\mathrm{p}<0.001) \quad$ and $\quad$ socioeconomic empowerment component $(1.71 \pm 0.89$ versus $1.13 \pm 1.08, \mathrm{p}<0.001)$. The $\mathrm{OR}$ of total woman empowerment score was 1.3 , 95\% CI, (1.2-1.4).

As shown in Table 4, after adjusting for all the factors that were significantly associated with better ANC utilization $(\geq 4$ versus ANC visits) in Tables 1 through 3 namely residence, education, occupation, income, spouse involvement, all significant ANC barriers and lastly total women empowerment, having spouses accompanying mothers during their ANC visit was significantly and independently associated with better ANC utilization in multiple regression analysis $(\mathrm{OR}=6.40$, 95\% CI, 2.3-18.1). Other significant factors ANC utilization in multiple regression analysis included living in urban areas, higher education, transportation cost, and bad attitude of caregivers.

\section{Discussion}

We are reporting a positive impact of spouse involvement in ANC services and women empowerment on antenatal care utilization among a group of mothers living in both urban and rural regions of Egypt and attending primary care services. Like our findings, previous studies showed that partner's involvement in seeking timely ANC is likely to improve the utilization of antenatal services. ${ }^{5}$ For example, it has been reported that partner involvement in pregnancy can increase utilization of ANC 1.5 times among American women. ${ }^{15}$ Men's involvement in ANC is intended to motivate husbands to support women's care from pregnancy, to delivery, and throughout the postnatal period. $^{2}$ Similarly, previous studies showed that women's autonomy has a positive effect on maternal health service utilization especially the ANC services. ${ }^{9,16}$ For instance, women in Kenya who have participated in household decisions were more likely to utilize antenatal health service compared with those who did not have autonomy. ${ }^{17}$ Empowered women are more likely to negotiate and involve their husbands in ANC-seeking. In addition, women who were sole decision-makers may also be more capable of soliciting spousal 
prenatal support which carries a great impact on prenatal services utilization. Conversely, women with limited say or participation may prefer not to invite spouses who may otherwise restrict their ANC-seeking choices. ${ }^{9,16,17}$ Unlike men, women often lack decision-making power to allocate resources for healthcare seeking. ${ }^{18}$ That is why non-empowered women can have limited utilization of ANC services. In the current study, about two-thirds of the mothers had at least 4 ANC visits during their last pregnancy. According to Egypt Demographic Health Survey (EDHS), in 2014, more than eight in every ten mothers had at least four antenatal visits. Three-quarters of the mothers reported they had their initial ANC visit in the first three months of pregnancy. ${ }^{7}$ In sub-Saharan Africa, approximately $69 \%$ of pregnant women receive at least one ANC visit, and $44 \%$ receive at least four ANC visits. ${ }^{2}$ In Brazil, it has been reported that the rate of adequate prenatal care use increased from $47.3 \%$ to $58.2 \%$ during the last decade and currently $60.5 \%$ of the women attended six or more prenatal visits and $66 \%$ started prenatal care during their first trimester of pregnancy. ${ }^{19 .}$

Better ANC utilization in the current study was significantly associated with living in urban areas, higher education, working status, and enough income. Additionally, better ANC utilization was independently associated with living in urban areas and higher education. In agreement with the current finding, EDHS reported in 2014 that urban mothers were somewhat more likely to receive ANC, especially regular care, than rural mothers. ${ }^{7}$ Additionally, higher levels of education among women living in urban Slums in Bangladesh improved the likelihood of receiving ANC during pregnancy, because educated women are more aware of the benefits of ANC. ${ }^{20}$ Similarly, women in Tajikistan who have achieved secondary or higher education and those who have enough income were more likely to receive at least four ANC visits compared with women who have never attended school. ${ }^{21}$ In India, it has been reported that a growing wealth index significantly increases the likelihood of receiving regular ANC, which again shows the positive impact of higher economic status on the ANC score. $^{22}$

Mothers in the current study considered the following barriers to negatively impact adequate ANC utilization; lack of desire, no family mainly husband support, distant ANC services, perception of being a low risk pregnancy, limited transportation options, transportation cost, lack of a female provider, bad attitude of caregivers, religious factors, and concern about lack of a midwife. Similarly, in Ghana, age at delivery, family income, media exposure, attitude towards pregnancy, knowledge about the danger signs of pregnancy, husband's approval of ANC, and distance to the health facility were associated with ANC service utilization at any point during pregnancy. ${ }^{23}$ Additionally, poor geographic access to health facility, having many children, and unwanted pregnancy contributed to the increased probability that a woman in Cameroon will not have an ANC visit in the first trimester. $^{8}$ In Brazil, despite of the improved rates of adequate prenatal care use, social inequity persisted with both low maternal schooling and low family income, which continued to be associated with higher rates of inadequate prenatal care use. $^{19}$

In conclusion, the current study showed that spouse involvement in ANC services and women empowerment can have a positive impact on antenatal care utilization among a group of mothers living in both urban and rural Egypt. More research is needed to examine locally acceptable strategies that can improve spouse involvement and women empowerment, also whether spouse involvement of the same educational level, have an impact on ANC utilization 
or not. This study has some limitations; the cross-sectional design of the study did not permit assessment of the causal relation of variables and reporting data from women who delivered within the previous six months may lead to reporting biases. Furthermore, empowerment information should be obtained from both the women and her spouse to give a clearer picture however that was unavailable.

\section{Conflict of interest: none}

Sources of funds: none

Key messages:

- Spouse involvement in ANC services and women empowerment can have a positive impact on antenatal care utilization among a group of mothers living in both urban and rural Egypt.

- The benefits of $A N C$ were reported by the majority of mothers

- The most imported reported barriers to antenatal care utilizations were lack of family support, lack of desire to use ANC, and transportation cost.

\section{References}

1. Firoz T, Chou D, von Dadelszen P, Agrawal P, Vanderkruik R, Tunçalp O, et al..Measuring maternal health: focus on maternal morbidity. Bull World Health Organ 2013; 91:794-796.

2. Lincetto $\mathrm{O}$, Mothebesoane-Anoh $\mathrm{S}$, Gomez P, Munjanja S. 2006. Antenatal Care: Chapter 2. In Opportunities for Africa's Newborns. Accessed on February 01, 2017. [http://www.who.int/pmnch/media/publicatio ns/aonsectionIII_2.pdf]

3. Gravett CA, Gravett MG, Martin ET, Bernson JD, Khan S, Boyle DS, et al.. Serious and life-threatening pregnancy-related infections: opportunities to reduce the global burden. PLoS Med 2012; 9: e1001324.

4. Satti H, Motsamai S, Chetane P, Marumo L, Barry DJ, Riley J, et al.. Comprehensive approach to improving maternal health and achieving MDG 5: report from the mountains of Lesotho. PLoS One 2012; 7: e42700.

5. Chattopadhyay A. Men in maternal care: evidence from India. J Biosoc Sci 2012; 44:129-153.

6. Goldie SJ, Sweet S, Carvalho N, Natchu UCM, Hu D.. Alternative strategies to reduce maternal mortality in India: a costeffectiveness analysis. PLoS Med 2010; 7:1.

7. Egypt Demographic and health Survey 2014 . Cairo, Egypt: Ministry of Health, ElZanaty and Associates, and Macro International.

8. Nkuoh GN, Meyer DJ, Tih PM, Nkfusai J. Barriers to men's participation in antenatal and prevention of mother-to-child HIV transmission care in Cameroon, Africa. J Midwifery Womens Health 2010; 55:363369.

9. Singh K, Bloom S, Haney E, Olorunsaiye C, Brodish P. Gender equality and childbirth in a health facility: Nigeria and MDG5. Afr J Reprod Health 2012; 16:123-129.

10.Haque SE, Rahman M, Mostofa MG, Zahan MS. Reproductive health care utilization among young mothers in Bangladesh: does autonomy matter? Womens Health Issues 2012; 22:171-180.

11.United Nations Women (UNWomen). 2011. Women's empowerment principles: Equality means business. Second edition. Accessed on February 01, 2018 [http://weprinciples.unglobalcompact.org/file s/attachments/EN_WEPs_2.pdf].www.dssres earch.com

12.Fahmy S, El-Sherbini AF. Determining simple parameters for social classifications for health research. Bull High Inst Public Health 1983; 13:95-108.

13.Jennings L, Na M, Cherewick M, Hindin M, Mullany B, Ahmed S. Women's empowerment and male involvement in antenatal care: analyses of Demographic and Health Surveys (DHS) in selected African countries. BMC Pregnancy Childbirth 2014; 14:297.

14. Martin LT, McNamara MJ, Milot AS, Halle T, Hair EC. Effects of father involvement on receipt of perinatal care and maternal smoking. Matern Child Health J 2007; 11:595-602.

15.Kwambai TK, Dellicour S, Desai M, Ameh CA, Person B, Achieng F, et al. Perspectives of men on antenatal and delivery care service utilization in rural western Kenya: a qualitative study. BMC Pregnancy Childbirth 2013; 13:134.

16. Nanjala M, Wamalwa D. Determinants of male partner involvement in promoting deliveries by skilled attendants in Busia, Kenya. Glob J Health Sci 2012; 4:60-67. 
17.Mistry R, Galal O, Lu M. Women's autonomy and pregnancy care in rural India: a contextual analysis. Soc Sci Med 2009; 69:926-933.

18. Bernardes ACF, da Silva RA, Coimbra LC, Alves MT, Queiroz RC, Batista RF, et al. Inadequate prenatal care utilization and associated factors in São Luís, Brazil. BMC Pregnancy Childbirth 2014; 14:266.

19. Russell Kabir, Hafiz Khan TA. Utilization of Antenatal care among pregnant women of Urban Slums of Dhaka City, Bangladesh. IOSR J Nurs Health Sci 2013; 2: 15-19.

20.Kamiya, Y. Endogenous Women's Autonomy and the Use of Reproductive
Health Services: Empirical Evidence from Tajikistan, Ph.D. Thesis, Osaka School of International Public Policy, Osaka University, Japan.2010

21.Bloom SS, Wypij D, Gupta. Dimensions of Women's Autonomy and the Influence on Maternal Health Care Utilization in a North. Indian City. Demography 2001; 38: 67-78. 22.Abor PA, Abekah-Nkrumah G, Sakyi K, Adjasi CKD, Abor J. The socio-economic determinants of maternal health care utilization in Ghana. Int J Soc Econ 2011; 38:628-648. 